\title{
EL DEPORTE Y LA INTEGRACIÓN SOCIAL EN IMÁGENES: MUJERES EN FORMA CONTRA LA EXCLUSIÓN
}

\author{
ANTONiO SANTOS ORTEGA \\ Universidad de Valencia \\ KeTY BALIBREA MELERO \\ Universidad. Politécnica de Valencia
}

Recibido: 21/01/2013

Aceptado: 27/03/2013

\section{Resumen}

El deporte puede convertirse en un medio para mejorar las condiciones de vida de colectivos vulnerables. Si se integra en un proyecto de intervención con estos grupos, puede aportar un buen número de ventajas, desde las propias sensaciones placenteras por su práctica, hasta las ventajas más relacionadas con el crecimiento del capital social o de hábitos saludables y mejora de la forma física. En el artículo, se exponen algunos resultados de una investigación en la que se ha estudiado cómo se puede utilizar el deporte con mujeres en situaciones de riesgo de exclusión, cuáles son sus problemas de cara a la práctica deportiva, qué es lo que esta les puede aportar, cómo se podría desarrollar un programa que llevase el deporte a las mujeres. En una segunda parte, se abre una reflexión sobre cuestiones metodológicas relativas al uso de la fotografía en la investigación social y se aportan algunas imágenes resultado de la investigación de la que procede este artículo.

Palabras clave: mujer, género, deporte, exclusión social

\begin{abstract}
The sport is a way to improve the living conditions of vulnerable groups. If it joins a project of intervention with these groups, can contribute a good number of advantages, from the own pleasant sensations in her practice up to the advantages most related to the growth of the «social capital» or of healthy habits and improvement of the
\end{abstract}


physical form. In the article, there are exposed some results of an iresearch in which there has been studied how it is possible to use the sport with women in situations of risk of exclusion, which are her problems with a view to the sports practice, in what is can contribute, how it might develop a program that was taking the sport to the women. In the second part, some ideas are opened on methodological questions relative to the use of the photography in the social research and some images are contributed proved from the investigation of which porcede this article.

Keywords: woman, gender, sport, social exclusion.

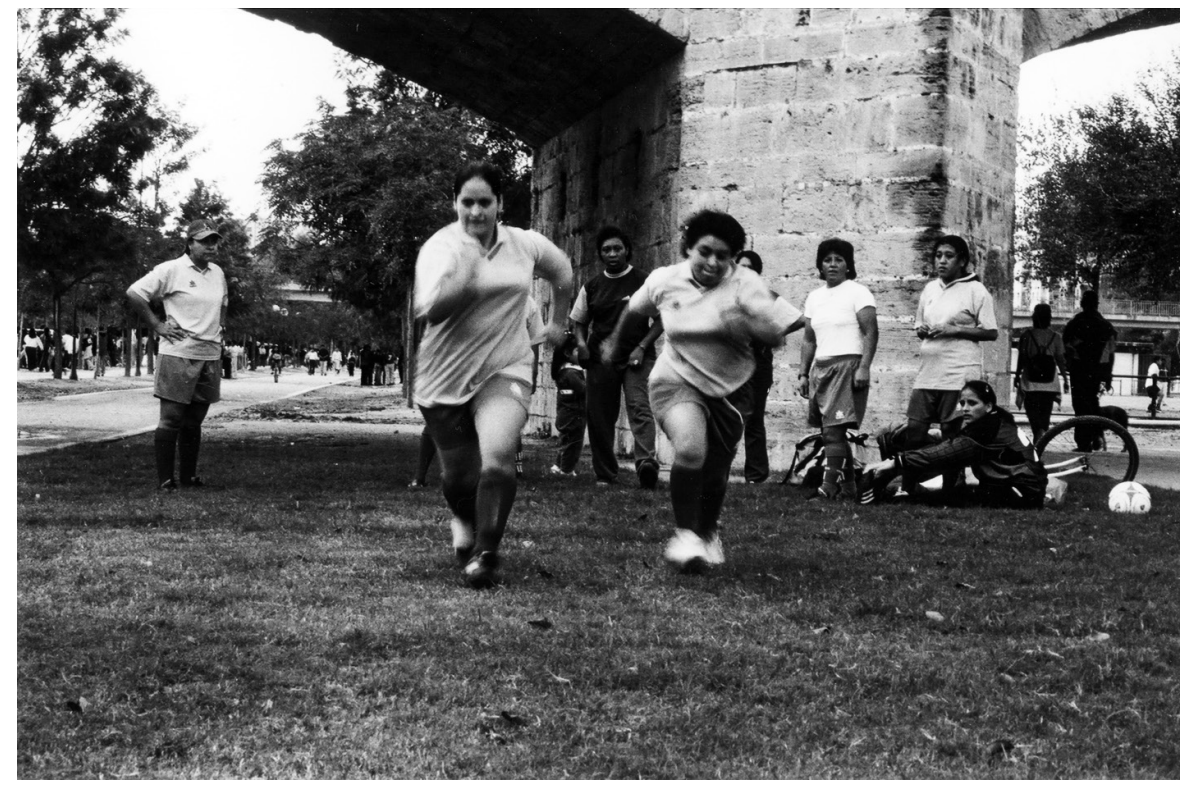

Feminismo/s 21, junio 2013, pp. 139-156 


\section{Introducción}

El título de este artículo recoge las tres palabras claves para describir su contenido: deporte, mujer, exclusión. Estas tres palabras ligadas resumen bien el contenido de lo que se tratará en este texto: el uso del deporte para mejorar las condiciones de vida de las mujeres más desfavorecidas socialmente.

Hay una cuarta palabra que destaca en el título: imágenes. Se presentarán aquí acompañando al texto, algunas fotografías procedentes del trabajo de campo de una investigación -Mujeres en forma contra la exclusión ${ }^{1}$ - en la que las imágenes tuvieron un papel importante como contribución activa a la producción de un discurso sociológico sobre las desigualdades deportivas de las mujeres.

En ese trabajo de campo, las fotografías sirvieron como una manera de tomar apuntes en el proceso de inmersión de los investigadores en el terreno de la práctica deportiva entre mujeres en situaciones de vulnerabilidad o exclusión. En este artículo, se dedicará un primer apartado a discutir justamente cómo el deporte puede contribuir a mejorar las condiciones de vida y de integración social para estas mujeres. Un segundo apartado será dedicado a reflexionar sobre las imágenes fotográficas y su lugar en la investigación social, en concreto en su aportación al análisis del deporte practicado por mujeres socialmente vulnerables.

\section{Deporte para luchar contra la vulnerabilidad social}

En estos últimos veinte años, las políticas sociales han incorporado el deporte para intervenir sobre áreas tradicionales de la acción social y sobre los problemas sociales más recientes de la exclusión social. El deporte aporta en estos terrenos una visión innovadora, que se suma a las herramientas clásicas de los profesionales de lo social. Los especialistas en la materia han constatado estas potencialidades del deporte y han comenzado a organizar programas

1. SAntos, Antonio. BAlibrea, Kety. y otros (2004) Mujeres en forma contra la exclusión, Dirección General de la Mujer, Generalitat Valenciana. [http://www.uv.es/dis/1.pdf, consultada el 1-10-2012] 
deportivos para desarrollar la cohesión social en zonas urbanas desfavorecidas, para reducir la violencia y mejorar las relaciones interétnicas o intergeneracionales, para rehabilitar a reclusos, o para mejorar la animación y la participación social de otros colectivos con discapacidades².

Si nos ceñimos al caso más concreto de las discriminaciones deportivas que sufren las mujeres, las instituciones responsables en este terreno han hecho algunos esfuerzos por contrarrestar las profundas tendencias de desigualdad que se dan hacia la práctica femenina. Las medidas más conocidas para paliar la discriminación de género en el deporte se han dirigido a la población femenina en abstracto. Las preocupaciones fundamentales que se hallan tras estas medidas son de contenido generalista: promover el deporte de alta competición de las mujeres y el deporte olímpico, impulsar el acceso a cargos directivos, a tareas técnicas o, simplemente, aumentar el nivel de participación y reducir las discriminaciones. Sin embargo, nuestro interés en este artículo se concentra en analizar la práctica del deporte como medio de intervención sobre colectivos de mujeres en situación de precariedad social. Las desigualdades y discriminaciones que ellas sufren no tienen su origen meramente en la condición sexual, sino en aspectos como la clase social, la etnia o el hábitat. Sabemos que cuando estas desigualdades se ensamblan con el género, los problemas se agravan. El caso de una mujer pobre, perteneciente a una minoría étnica y que habite en un barrio periférico de una gran ciudad sería un buen ejemplo de cómo la suma de factores de exclusión agrava su realidad.

El cruce de los factores de género y las condiciones de vida define, así, nuestro objeto de investigación: mujeres con rentas bajas o en familias monoparentales con cargas familiares, mujeres inmigrantes, mujeres en contextos urbanos en crisis, mujeres con problemas delictivos, con bajos niveles educativos. Todas ellas acumulan problemas específicos que en general agravan las discriminaciones de género y que habrían de ser considerados concretamente a la hora de emprender iniciativas de política social destinadas a resolverlos.

En este sentido, la incipiente aplicación de la actividad física y deportiva en los programas de lucha contra las desigualdades de género, se está revelando como un recurso que podría mejorar la autonomía, la identidad y la salud de las mujeres. Aunque estas intervenciones se encuentran en una etapa inicial, los resultados que se avanzan ratifican que el deporte puede contribuir

2. Ver sobre estos aspectos: HeINEMANN, Klaus. «Deporte para inmigrantes: ¿instrumento de integración?» Apunts. Educació Física i Esport, nº 68, (2002); y SANTOS, A. «Exclusión social y deport», Barcelona Metropolis no 81, (2011), pp. 57-59; y

<http://w2.bcn.cat/bcnmetropolis/arxiu/es/page6a69.html?id=23\&ui=476\&prevNode $=33 \& \operatorname{tag} I d=243>$, consultada 13-11-2012 
a fortalecer los vínculos sociales. El futuro de estas líneas de actuación es alentador y están destinadas a tener un peso mayor en las políticas sociales.

\subsection{Perfiles de vulnerabilidad: los obstáculos para la práctica de la actividad física de las mujeres socialmente desfavorecidas}

En estos últimos años, la práctica deportiva se ha revelado como un importante factor sociocultural en nuestras sociedades contemporáneas. En muchas de sus actuales manifestaciones, el deporte es un reflejo de la sociedad, su estudio permite captar los cambios en la estructura social y en los deseos de los individuos que la componen. El deporte ha penetrado en lo cotidiano, ha aumentado su práctica en segmentos crecientes de la población, ha visto multiplicar los tipos de actividad deportiva y, en general, se ha popularizado. Sin embargo, existen grupos que podríamos considerar excluidos de esta 'democratización' deportiva. Las clases sociales más humildes y las mujeres tienen un lugar subalterno en este avance triunfal de un deporte que promete salud, ocio, identidad, diversión. Las tasas de participación de ambos grupos están muy por debajo de la media, pero más importante que este dato cuantitativo, sería el analizar la persistencia de estructuras culturales que definen posiciones excluidas en el ámbito de lo socio-deportivo. Estructuras culturales que contribuyen a definir una normalidad social en la que hay algunos grupos que están ausentes de la práctica deportiva y esto apenas plantea preguntas a nadie.

Los grupos sociales de extracción más humilde muestran tasas más bajas de participación. Según la Encuesta de Hábitos Deportivos 201033, practica deporte el 56\% de los encuestados de clase alta frente a un 30\% de los situados en la base de la pirámide social. En determinados colectivos de mujeres esto se expresa hoy de manera evidente y contundente: mujeres con ingresos o niveles de estudios bajos o mujeres en familias monoparentales con cargas familiares, mujeres inmigrantes, mujeres en contextos urbanos en crisis. Estamos hablando de los grupos más desfavorecidos, que en estos últimos años de crisis están viviendo situaciones socioeconómicas muy difíciles. En todas ellas, se condensan nuevos rasgos de discriminación.

Hoy en día el binomio mujer-deporte provoca una reacción de extrañeza social cuando la mujer pertenece a las clases populares. Nadie prefigura a estas mujeres realizando un deporte. Este es, sin duda, el mejor indicador de la

3. GARCÍA FERRANDO, Manuel y LlOPIS, Ramón. Ideal democrático y bienestar personal. Encuesta sobre los hábitos deportivos en España 2010. Madrid, Consejo Superior de Deportes y Centro de Investigaciones Sociológicas, 2011. 
exclusión de un grupo. El excluido es invisible y no despierta apenas ninguna preocupación social real. A pesar de que se escuchan a menudo las ventajas del deporte y de la actividad física, nadie se pregunta por qué un segmento de la población tiene prácticamente vedado su acceso. Los complejos mecanismos sociales de la dominación acaban imponiendo representaciones colectivas en las que se percibe como normal la exclusión de estos grupos de mujeres de la esfera del deporte. Se naturaliza, se considera como lógico, como propio del orden de las cosas, lo raro sería casi lo contrario.

Por su parte, los grupos excluidos acaban interiorizando estas representaciones y sobrellevando, mejor o peor, la imagen que las define como ausentes de la actividad física. El lugar que se les asigna es el de la familia y el trabajo y parece incompatible mezclarlo con actividades que resten tiempo a estas dedicaciones para las que parecen haber nacido. Para las mujeres con escasos recursos hacer deporte sería como robar a la familia un tiempo que se le debería haber dedicado. La fuerza del estereotipo de la mala madre recaería sobre ellas ${ }^{4}$.

Además, las mujeres de las clases populares están habituadas a hacer un uso 'laboral' de su cuerpo. Sus trabajos son manuales y, generalmente, muy físicos. Frecuentemente, su relación con el cuerpo se rige por la lógica de «hasta que el cuerpo aguante»; el esfuerzo y la fatiga están ligadas al trabajo y los pequeños dolores y otras molestias corporales son minimizadas o silenciadas. Este vínculo entre la actividad física y el trabajo aleja a las clases populares de la actividad deportiva y cuando esta se produce se caracteriza por ser de gran dureza física y realizada en equipo.

A las cargas mentales que imponen las representaciones y los estereotipos de género hay que agregarles las cargas materiales que, en el caso de las mujeres peor situadas en la estructura de clases no son pocas: cuidados familiares- niños y mayores-, trabajo dentro y fuera de casa, bajos ingresos. Además, animarse a realizar una actividad física supondría tiempos y costes añadidos: transporte, inscripción al gimnasio, cuidado de niños durante su ausencia. Una buena red de servicios públicos ayudaría, pero hasta ahora no ha sido una

4. Incluso entre las amas de casa en general, sea cual sea su condición económica predominan este tipo de representaciones negativas. Sobre ellas recae la idea extendida de que quien no tiene un empleo asalariado -como es su caso- no tendría derecho tampoco a una esfera legítima de ocio autónomo y por tanto a la posibilidad de optar por emplearlo en actividades como podrían ser las deportivas. Esto condena a las amas de casa a tener las tasas de práctica deportiva más bajas, por debajo del 20\%, cuando las de mujeres más jóvenes y ocupadas se encuentran entre un 40-50\%. Conforme avanza la edad de las amas de casa, más se aleja la posibilidad de realizar alguna actividad física y se dificulta la capacidad de auto-representarse en situación deportiva. 
prioridad de los gobiernos. Mucho tiene que gustar el deporte para practicarlo en estas condiciones.

El marco que se acaba de describir puede ser común a buena parte de las mujeres en las que se ha concentrado nuestra investigación. Las que encabe$z$ an hogares monoparentales ${ }^{5}$ las que viven en hogares con bajos ingresos ${ }^{6}$ son el corazón de esta exclusión económica que estamos tratando, pero a estas manifestaciones de la exclusión pueden añadírsele otras nuevas dificultades menos marcadas por lo económico. La falta de integración social de las mujeres inmigrantes podría ser una de ellas ${ }^{7}$. La manera en que este déficit de integración se expresa es mediante una carencia de vínculos familiares o sociales: tener los maridos, hijos o amigos lejos es también un indicador de pobreza, en este caso de las relaciones sociales. Si hacer deporte significa hacer amigos, facilitar su práctica sería una forma de luchar contra la exclusión ${ }^{8}$.

A la hora de actuar sobre estos grupos de mujeres cercanas a la franja de la exclusión se han dirigido diversas líneas de política social orientadas a incidir fundamentalmente sobre su situación económica, laboral o educativa. Los programas de rentas garantizadas, de ayudas familiares a hogares monoparentales, de formación ocupacional o de incentivos dirigidos a facilitar la contratación laboral son algunos de los más conocidos. Sin embargo, cada vez

5. El número de familias formadas por un adulto que vive solo con hijos menores está creciendo considerablemente en España. El 90\% de estos hogares monoparentales están encabezados por mujeres. Los datos de la encuesta de población activa, elaborada por el Instituto Nacional de Estadística, ponen de relieve que en 2002 se contabilizaban 273.000 de estas familias encabezados por mujeres. A finales de 2011, la cantidad asciende a 486.000 , en los que viven más de 770.000 niños y adolescentes. Estos hogares tienen tasas de riesgo de pobreza muy por encima de la media.

6. Los hogares españoles por debajo del umbral de pobreza suponen en 2011 el 21,8\%, lo que equivale a 3,8 millones de núcleos familiares. Estos hogares están situados mayoritariamente en zonas urbanas degradadas -áreas periféricas o centros históricos deteriorados-. La tasa de riesgo de pobreza alcanza el $38.9 \%$ en hogares de una sola persona con hijos a cargo. La mayor parte de estos encabezados por mujeres.

7. El número de mujeres inmigrantes ha crecido a un ritmo muy fuerte en la década previa a 2007. A mediados de 2012, representan el 48\% del total de los residentes extranjeros en España -en torno a 2,5 millones según los datos de la Secretaría General de Inmigración y Emigración del Ministerio de Empleo y Seguridad Social. En el grupo latinoamericano, las mujeres tienen una presencia mayoritaria, en torno al $60 \%$ del total, mientras que en el colectivo del marroquí son solo un $40 \%$. Esta composición interna por sexo unida a los factores culturales y religiosos apunta dificultades diferentes de cara a la integración entre las distintas nacionalidades de procedencia.

8. La cuestión de la inmigración y el deporte ha sido tratada en: MAZA, Gaspar. «El deporte y su papel en los mecanismos de reproducción social de la población inmigrada extranjer», Apunts. Educació Fisica i Esports, nº 68, (2002); y MEDINA, X. «Esport, immigració i interculturalitat», Apunts. Educació Fisica i Esports nº68, (2002). 
existe una mayor demanda, desde los servicios sociales, de encarar no solo económicamente los procesos de integración de estas mujeres. El deporte podría ser un recurso complementario eficaz. La actividad física acumula otros tipos de ventajas que, sumadas al tratamiento económico de sus situaciones de pobreza, podrían resultar provechosas para mejorar sus condiciones de vida.

De forma resumida, el deporte utilizado con estas mujeres podría dar respuesta, al menos, a cuatro dificultades que se derivan de sus problemas que hemos esbozado arriba:

- Reforzar la valoración personal

- Conocer y cuidar el cuerpo

- Establecer nuevas relaciones, consolidar un grupo

- Favorecer la inserción profesional

El deporte es una buena baza para alcanzar estas mejoras para las mujeres. Hay que comentar previamente que para desarrollar estas cuatro finalidades es necesario contar con iniciativas desde el mundo asociativo, los servicios sociales y la política social en general que puedan aprovechar las prometedoras ventajas del deporte. La planificación y los apoyos externos son, por tanto, esenciales para poner en marcha este tipo de experiencias. Las mujeres no decidirán embarcarse en la práctica deportiva si no existen las condiciones oportunas, es decir, si no se activa una red de servicios públicos que cubra el transporte, el cuidado de los otros miembros de la familia, la oferta y el coste de la actividad, los aspectos técnicos, etc. ${ }^{9}$

Por lo que se refiere a la primera de las mejoras mencionadas arriba -el refuerzo de la valoración personal-, la actividad física resulta un generador de autoestima. La elección de la práctica, la realización de una actividad que exige esfuerzo y superación, la mejoría del estado físico contribuyen a estimular la capacidad de decisión y a dar solidez a la identidad personal. Cuando se práctica una actividad deportiva se siente que da un aliciente a la jornada diaria. Siempre que la práctica sea atractiva, bien programada y permita ampliar

9. Entre las medidas que recientemente ha puesto en marcha el Consejo Superior de Deportes en el marco de su Plan $\mathrm{A}+\mathrm{D}$, se encuentra la realización de una guía para la puesta en marcha de experiencias de deporte-inserción social. Además de múltiples ideas, en la guía, pueden consultarse algunos principios básicos de gestión para emprender iniciativas de este tipo. Existe una versión electrónica. Gaspar Maza Gutiérrez (coord.) (2010) Deporte, actividad física e inclusión social. Una guía para la intervención social a través de las actividades deportivas. Consejo Superior de Deportes, Madrid. (Consultada 1311-2012. http://www.planamasd.es/sites/default/files/programas/medidas/actuaciones/ WEB-GUIA+I.pdf) 
los contactos y las oportunidades, se espera con interés el momento de realizarla. ¿Por qué no extender estos beneficios entre las mujeres cuya autoestima encuentra más dificultades para estar fuerte?

En cuanto a la segunda dificultad referida al conocimiento y cuidado del cuerpo, la actividad física es un medio privilegiado de aprendizaje corporal. No hay que olvidar que el cuerpo es el soporte biológico de las relaciones sociales y que su conocimiento no es automático. Realizar actividad física contribuye a dotar a la persona de una sociabilidad corporal más cuidada. Entre otros aspectos, esta mejora de la sociabilidad permite manejar las «técnicas corporales»-gestos de eficacia práctica y simbólica socialmente enraizados: nadar, montar en bici, conducir-; aprender los gestos de interacción social -tocar, mirar, acercarse-; controlar la expresión de sentimientos -vergüenza, dolor-. La pura motricidad y el lenguaje social del cuerpo están estrechamente unidos y se expresan de forma diferente en cada cultura. En nuestra investigación hemos analizado algunos estudios de caso en los que se puede observar bien el efecto de la actividad física en las mujeres magrebíes, con limitaciones sociales al conocimiento y la expresión corporal. La actividad deportiva constituye para ellas una ampliación de la propia cultura corporal, un conocimiento de los hábitos corporales del nuevo lugar de residencia y un cuidado físico personal.

La tercera línea de actuación del deporte facilitaría a las mujeres establecer nuevas relaciones, consolidar un grupo. Una de las demandas que entre ellas se expresa abiertamente es la soledad y la falta de contacto con otras personas. La situación de muchas mujeres inmigrantes es muy reveladora a este respecto. Tienen trabajo -demasiado incluso-, gracias a ello, disponen de ciertos ingresos, pero les falta tiempo para disfrutar y espacios en los que se puedan reunir para compartir experiencias y soledades. Para ellas, el fútbol puede representar y representa -si atendemos a las investigaciones emergentes sobre el tema- este elemento de cohesión grupal, de identidad cultural y de refuerzo afectivo ${ }^{10}$.

Estas ventajas se podrían extender al resto de mujeres en situaciones de vulnerabilidad más allá de su pertenencia étnica. Podría ser así una herramienta para potenciar la participación y el asociacionismo. Por ejemplo, en el barrio -espacio de vecindad y cercanía para las mujeres-, donde se puede conjugar el deporte con preocupaciones centrales en la vida del barrio y de

10. Para una información más detallada puede verse: DuRÁn, Javier. (coord.) Actividad física, deporte e inmigración. El reto de la interculturalidad. Dirección General de Deportes, Comunidad de Madrid, 2009 y LlEIXÁ, Teresa y SOLER, Susana. Actividad física y deporte en sociedades multiculturales ¿integración o segregación? ICE- Horsori, Barcelona, 2004. 
sus asociaciones. Las actividades deportivas dan identidad al barrio y unir a un grupo de mujeres de la zona a través del deporte no es una utopía ${ }^{11}$. Además del vecindario, la escuela podría ser un lugar también cercano a las mujeres y un posible escenario de actividades deportivas que potenciasen la participación y, además, la cohesión familiar. Las actividades realizadas junto a los niños y a otras madres en locales de la escuela o al aire libre -excursiones- contribuirían a una mejor integración social aprovechando los tiempos y los espacios cotidianos de estas mujeres. En algunos casos, se han planificado actividades que plantean conjuntamente actividad física o lúdico deportiva de los niños, conjugada con la de las madres mediante bonos o cheques mixtos para casar mejor 'tiempos deportivos' y tiempos familiares. Todas estas propuestas permitirían aplicar el deporte sin que tengan las mujeres la sensación de estar restando tiempo a sus 'obligaciones' familiares. Por otra parte deberían ser planteadas pensando en la implicación de los varones, no crear guetos y avanzar hacia una conciliación del deporte y la vida familiar que incluya a ambos sexos.

La cuarta línea de actuación da un paso más en cuanto a las potencialidades integradoras del deporte y se acerca a las necesidades de estas mujeres. Se trata de las posibles vías de inserción profesional que contiene la práctica deportiva. El deporte es un gran generador de empleo. Desde su difusión masiva como actividad de ocio o salud, se ha convertido en un sector de actividad económica. Recientemente, se han desarrollado nuevas figuras educativas que pueden desembocar en salidas profesionales: animación deportiva, monitores de actividad física, educadores deportivos, técnicos de atención a la salud, dietas, masajes. Las políticas de empleo han incluido entre los yacimientos de empleo nuevas necesidades que requieren este tipo de perfiles formativos con ciclos breves y de carácter muy aplicado: atención a ancianos, animación juvenil, actividades al aire libre, mediación y resolución de conflictos en zonas urbanas desfavorecidas, entre otros. El conocimiento de primera mano de estas mujeres podría dirigirse hacia una tarea profesional, aunque habría que velar porque estos empleos no pasasen a reforzar más su papel de atención y cuidado a niños y ancianos que ya desarrollan en su ámbito doméstico. La formación y la profesionalización serían imprescindibles para ello.

Desde las políticas de empleo, podrían planificarse acciones dirigidas a las mujeres en las cuales se combinase lo deportivo, lo formativo y lo laboral y aprovechar este potencial de inserción profesional tan prometedor. Las

11. Balibrea, Kety., Santos, Antonio. Deporte en los barrios: integración o control social, Ed. Universitat Politècnica de València, Valencia, 2011. 
mujeres podrían encontrar empleos o mejorar sus expectativas laborales a través del deporte. En algunos de los casos que hemos estudiado, se pueden trazar trayectorias de mujeres que comenzaron por participar en un programa de actividad deportiva, para pasar posteriormente a colaborar voluntariamente, cursar un programa formativo breve y encontrar un empleo. Es cierto que los actuales recortes sociales frenan la expansión de estas necesidades sociales y que, en este clima postwelfarista, suena utópico pensar en una ampliación del sector social.

Cerramos este apartado con una última reflexión sobre la aplicación por parte de las políticas sociales de posibles proyectos de intervención deportiva con mujeres. Si las actividades deportivas planteadas generan el placer de los participantes, el disfrute físico y el enfrentamiento lúdico respetando unas reglas de juego, tienen ya una legitimidad suficiente, incluso más allá de cualquier planteamiento racional de intervención integradora. Si contribuyen a acrecentar el gusto por vivir, están promoviendo ya aspectos fundamentales en términos de autoestima, energía personal y vínculo social. Aunque para los animadores deportivos el deporte pueda ser adoptado como un medio para la integración, tienen que actuar como si fuera un fin en sí mismo, una fuente de placer en sí. Los educadores-monitores que se ocupasen de estas iniciativas de integración por el deporte no pueden dar prioridad a la relación asistencial contenida en esos proyectos, sino que han de compartir momentos existenciales con las mujeres. La intervención tiene que estar guiada por el reconocimiento y la aceptación, sin pedir grandes logros, ayudando a las mujeres a esclarecer los procesos complejos en los que se hallan inmersas, fruto de sus contextos sociales vulnerables o en fases existenciales conflictivas. La integración solo es posible si se crea un marco de igual dignidad. El deporte no tiene ninguna virtud intrínseca de por sí. Es como una herramienta en manos de un artesano, depende de quién y cómo la use, así serán los resultados.

Hay que comentar también la importancia de subrayar y enclavar el papel modesto del deporte en el conjunto de problemas estructurales de desigualdad que viven los colectivos desfavorecidos. Si la coyuntura y la estructura social se caracterizan por una fuerte presencia de actitudes racistas, xenófobas, clasistas o machistas, el deporte poco podrá hacer por cambiar esta realidad. Pero al menos, hay que apostar por utilizarlo para mejorar las condiciones de vida de los colectivos afectados por estas actitudes. Así, tendremos un recurso que pueda contribuir a su bienestar e integración social e incluso que pueda servir para conseguir pequeños cambios sociales. En esta línea, el uso de la actividad física y deportiva puede mejorar la autonomía, la identidad, la salud de las mujeres y la lucha contra la discriminación. 
2. Visibilizar el deporte de las mujeres vulnerables: Reflexiones sobre el uso de las imágenes fotográficas en la investigación social

Las imágenes que ilustran este artículo proceden del trabajo de campo de la investigación referida en la primera página del presente artículo ${ }^{12}$. En ella se estudiaron casos concretos de intervención a través del deporte con mujeres en situación social desfavorecida. En la recogida de información sobre el terreno se realizaron numerosas fotografías con vistas a organizar una exposición posterior. Se integró un fotógrafo en el equipo de investigadores. Conforme avanzaba esta labor fotográfica, crecía la necesidad de profundizar metodológicamente sobre la fotografía. Las imágenes entraban en diálogo con el texto escrito. Además del potencial propio de la fotografía y del texto, su fusión multiplicaba la fuerza de nuestro análisis: esclarecía elementos del

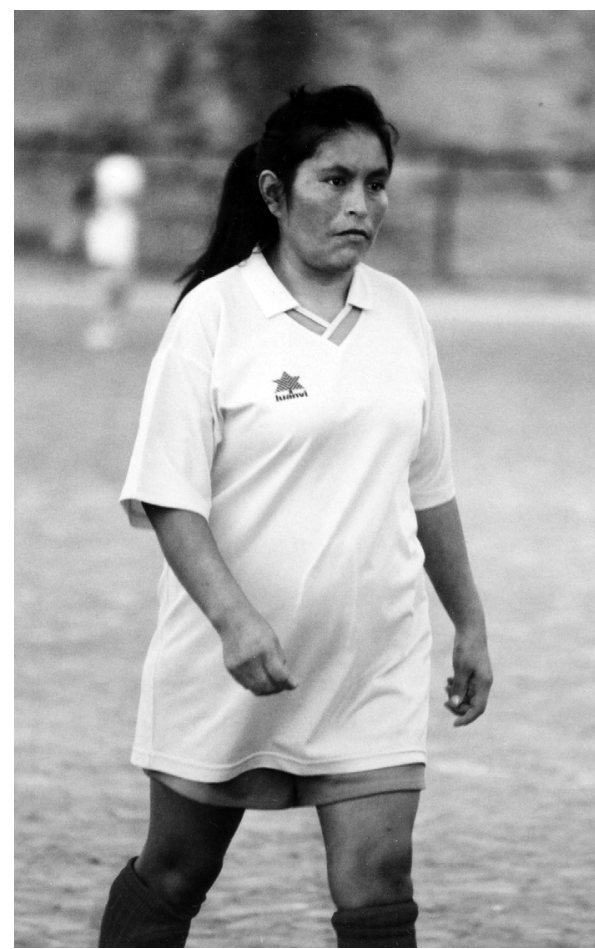
contexto que ayudaban en su descripción escrita; condensaba efectos y causas de procesos ofreciendo detalles inesperados; elucidaba aspectos que no salían a la luz en las conversaciones mantenidas con las mujeres entrevistadas. La imagen sugería gestos y detalles residentes en estratos preconscientes del actuar de las mujeres, que eran controlados en la interacción verbal, pero que quedaban fijados por la cámara. Más allá de la capacidad particular de la fotografía de sugerir e interpretar temas para quien la mira, en compañía del texto ampliaba las líneas de desarrollo de la investigación. Este es el motivo de aportar aquí algunas imágenes y de detenernos en algunas reflexiones sobre lo visual como método de investigación social.

12. Santos, Antonio, Balibrea, Ketty. y otros Mujeres en forma contra la exclusión, Dirección General de la Mujer, Generalitat Valenciana. 2004 [http://www.uv.es/dis/1.pdf, consultada el 1-10-2012]. 
El progresivo interés de la fotografía a lo largo de la realización del informe provenía de las posibilidades que ésta ofrecía para combinar el lenguaje escrito y el visual. Dos lenguajes complementarios que multiplican el potencial de descripción y análisis. La comprensión es narrativa y las dos formas de narración combinadas la mejoran. A través de la imagen, el texto se comprende mejor y viceversa. Conseguir la continuidad entre ambos lenguajes es pues un trabajo añadido y prometedor de cara al resultado final del informe.

En las ciencias sociales, el uso de la fotografía no ha sido tan frecuentado como se podría imaginar dadas sus potencialidades. El cientifismo y el positivismo típicos del método científico la han relegado a un lugar subalterno. La sospecha de subjetivismo, que siempre se le atribuye, está reñida con la severa exigencia de la objetividad científica. A pesar de ello, las incursiones de la fotografía en el terreno del conocimiento científico han sido muy brillantes. Desde el comienzo del siglo XX, la fotografía social se ha combinado con las ciencias sociales para documentar las condiciones de vida de grupos humanos. En el primer tercio de siglo, la tradición documental norteamericana trazó un retrato sobre las clases pobres que cuadra a la perfección con los análisis que en la década de los treinta realizase la escuela de Chicago, un momento de particular creatividad de la Sociología. En ese periodo, Lewis Hine recorrió buena parte del país registrando la dura situación del trabajo de los niños, la fuerza de sus fotografías combinadas con su formación como sociólogo influyeron de manera determinante en el cambio de legislación sobre el trabajo infantil en Estados Unidos. Este ejemplo muestra cómo la fotografía va más allá del papel subalterno e ilustrativo que frecuentemente se la ha dado desde las ciencias sociales. La simplificación de los equipos fotográficos dió un giro al clásico trabajo de campo de los antropólogos: Bronislaw Malinowski, Margaret Mead y Gregory Bateson demuestran en sus estudios el poderoso instrumento de investigación que la fotografía resulta ser.

Más recientemente, Pierre Bourdieu ${ }^{13}$ ha hablado de la fotografía como un «arte medio». Así tituló una vieja investigación realizada hace treinta años en la que se analizaba la difusión de la fotografía como práctica social de consumo. El título condensa perfectamente tres cualidades de la fotografía que se derivan de su investigación: «arte medio» porque en el momento de su investigación la fotografía es una práctica de las clases medias, medio porque se halla en un lugar intermedio entre el arte y la técnica y, finalmente, medio porque resulta ser un medio de expresión de los usos sociales de clase. Esta

13. Bourdieu, Pierre. Un Arte Medio: ensayo sobre los usos sociales de la fotografía. Ed.Gustavo Gili, Barcelona, 2003. 


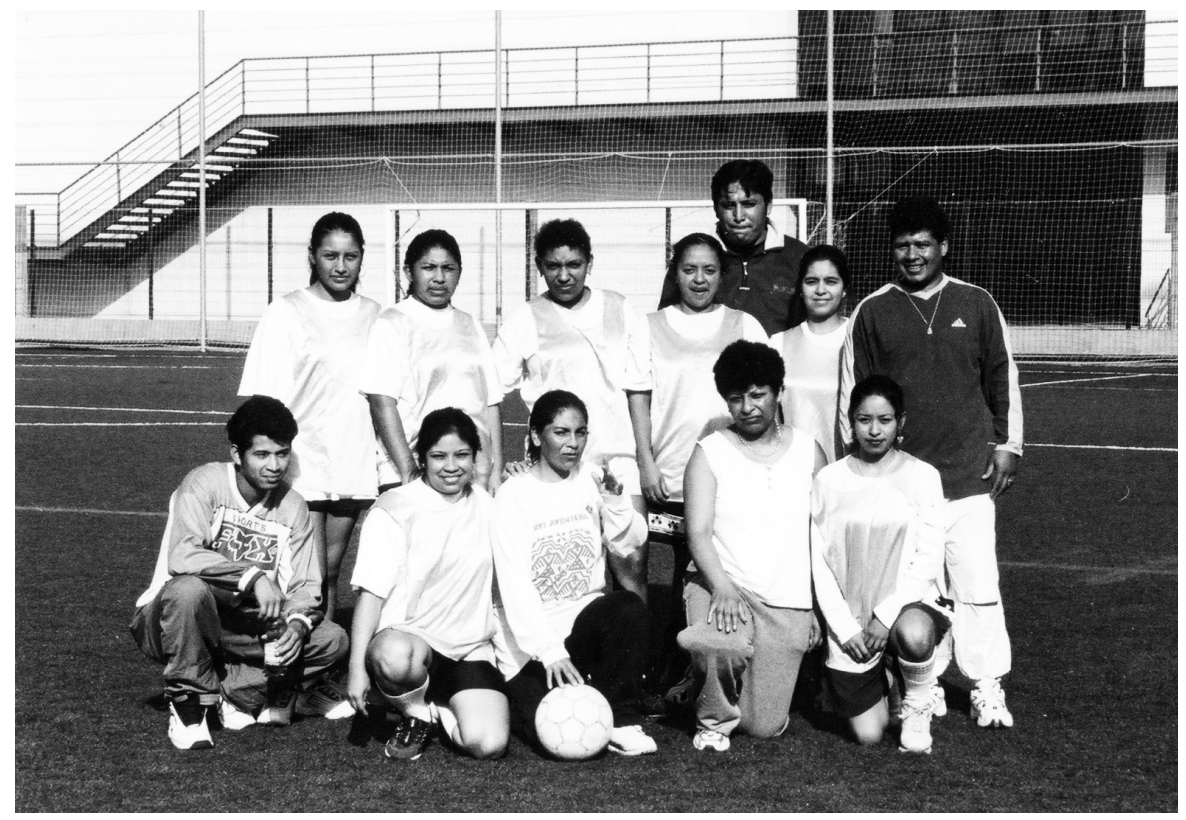

condición de «arte medio» es muy reveladora para el sentido de nuestra investigación que trata de explicar posiciones y procesos sociales por «medio» del lenguaje verbal y visual.

En un bonito símil, Moholy-Nagy comentaba que la fotografía se parece más a la poesía que a la pintura. Esta manera de entrelazar lo visual y lo verbal a través del lenguaje poético vuelve a acercarnos al planteamiento de conjugar texto y visión. Moholy-Nagy hablaba de la foto como una «visión intensiva», un lenguaje complementario y autónomo a la vez de la escritura. Más relevante aún en nuestro caso, donde el objeto de investigación -la práctica deportiva de las mujeres- introduce además un último nivel de lenguaje-el lenguaje del cuerpo-, con una poética propia que puede también encontrar su medio de expresión a través de la imagen o del texto. Así como el poema es solo el resultado final de todo un proceso creativo, de la misma manera, la característica fundamental de la imagen fotográfica no está en el resultado -la foto-, sino en la génesis de la imagen. Se trata por tanto de un proceso de producción y transmisión de conocimiento que para nosotros funciona además en paralelo a la elaboración del informe de investigación.

La capacidad penetrante de la imagen fotográfica transmite profundidad a cualquier investigación, la nuestra se ha beneficiado al menos de seis cualidades que la fotografía posee: 
La primera hace referencia a uno de los atributos más destacados por Roland Barthes ${ }^{14}$ para quien la fotografía representa un «mensaje visual» que puede ser vivido y leído como forma de ayudar a la gente a hablar de la gente, en definitiva, a hacer algo comprensible. De esta forma, la fotografía no es una observación pasiva, sino que promueve formas de participación que hacen a quien la mira cómplice del destino de otros. Hace memorable y da rostro a un proceso, que en nuestro estudio es el de la exclusión. En el mejor de los casos, la foto es un revulsivo para la toma de posición moral. Hacer hablar y ampliar la comprensión son dos buenos resultados de lo que algunos llaman la elocuencia fotográfica y que nuestro informe trata de aprovechar.

La segunda cualidad está relacionada con su capacidad para captar evidencias. Al igual que una entrevista permite captar discursos o prácticas, la fotografía, en palabras de Susan Sontag ${ }^{15}$, permite apresar el mundo, es experiencia capturada, «miniaturas de la realidad», «fragmentos que constituyen el mundo». Estas sugerentes metáforas expresan bien la función de certificación de la fotografía: la foto nos remite realmente al objeto del cual deriva. Esta función de certificación es una de las bases de la prueba científica a la hora de buscar explicaciones y causas a los fenómenos. La fotografía como práctica ofrece una particular función de certificación: una buena foto siempre representa un indicio del objeto -que puede no verse-, un signo que lleva contenido un mensaje. Así, la imagen del humo es un indicio del fuego, aunque no se vea, o la de la sombra lo es de la presencia, aunque ésta no se distinga. La foto es pues un indicio, una representación del objeto, que en nuestro caso corresponde a los procesos de exclusión que tratamos de captar.

Una tercera cualidad de la fotografía se corresponde con su potencial para reflejar la tensión del conflicto. El fotográfico no es un lenguaje neutro, objetivo, selecciona y muestra intencionadamente parte de la realidad. En este sentido, la fotografía cumple una función de designación: señala con el dedo, ubica. Nuestras fotografías enfocan la exclusión social, que es un campo de fuerzas en conflicto. La profundidad de campo fotográfica, el encuadre, la superposición de planos son instrumentos para desvelarla.

Muy en relación con la anterior, la cuarta ventaja de la fotografía es su disposición para captar el contexto. Como ya sabemos, el nuestro es el de los entornos sociales en que se desarrolla la práctica deportiva de las mujeres. De forma armónica, nuestro informe los describe y la fotografía los capta.

14. BARTHES, Roland. La cámara lúcida. Nota sobre la fotografía. Paidós, Barcelona, 1989. 15. SontaG, Susan. Sobre la fotografía, Edhasa, Barcelona, 1981. 
A veces, el escenario donde se desarrolla la práctica habla por sí solo, en nuestro caso, los escenarios deportivos son definidos por el ambiente en que se integran, por el contexto: un estadio, un campo de arena, una explanada en el barrio, un rincón en una calle o, como en uno de nuestro casos, una cancha de fútbol de tierra en el cauce del Turia, que habla de mujeres latinoamericanas que juegan, rodeadas de ellas mismas y de todo su entorno. El material fotográfico que se ha recogido capta bien estos aledaños de la práctica deportiva. Debido a limitación del número de paneles en la exposición y al imperativo de seleccionar un número determinando de fotos, quizá pueda perderse esta riqueza del contexto. Sin embargo, el catálogo y este informe se acompañarán de un paquete de fotos más amplio que restituya la fuerza al contexto.

La quinta y no menos importante virtud de la fotografía es la de representar una obra abierta, sujeta a la interpretación por parte del espectador, que se vuelve actor. Así, la foto no es una mera copia de la realidad, sino que cuando el fotógrafo la capta ya incorpora una recreación de esa realidad que entonces es de segundo nivel, que lleva a un tercer nivel cuando a su vez la reinterpreta el público al que se dirige la fotografía. Este juego de meta-niveles nunca deja intacta la imagen inicial, que, aunque indeleble sobre el papel, cambia siempre que haya un observador que la reinterprete.

Finalmente, y de manera muy breve, la fotografía demuestra una considerable capacidad de síntesis y una gran utilidad a la hora de transmitir resultados. Su proverbial eficacia para condensar un significado la convierten en un medio ideal para comunicar un mensaje o un resultado. La misma capacidad de condensación que puede tener una frase reveladora en un discurso a la hora de explicar partes de su estructura, la tiene también la foto al congelar un pedazo significativo de la realidad.

\section{Conclusión}

Todas estas potencialidades de la fotografía se han mostrado en la investigación sobre mujeres y deporte de la que aquí hemos hecho un resumen. Aunque pocas en cantidad, las fotos que se han incluido evidencian el placer engendrado por la actividad física, el placer por el mero hecho de su realización, por el movimiento, por el disfrute de las sensaciones corporales, de la carnalidad en nuestras vidas. Entre estas mujeres, el deporte juega un papel de ocio muy creativo y de anclaje con el mundo. Frente a una vida nada fácil, el deporte representa la cara más positiva: una actividad autónoma que compensa la heteronomía que ellas sufren en el mundo laboral o en las dificultades familiares. Por otra parte, las fotos dejan traslucir el espíritu de grupo 


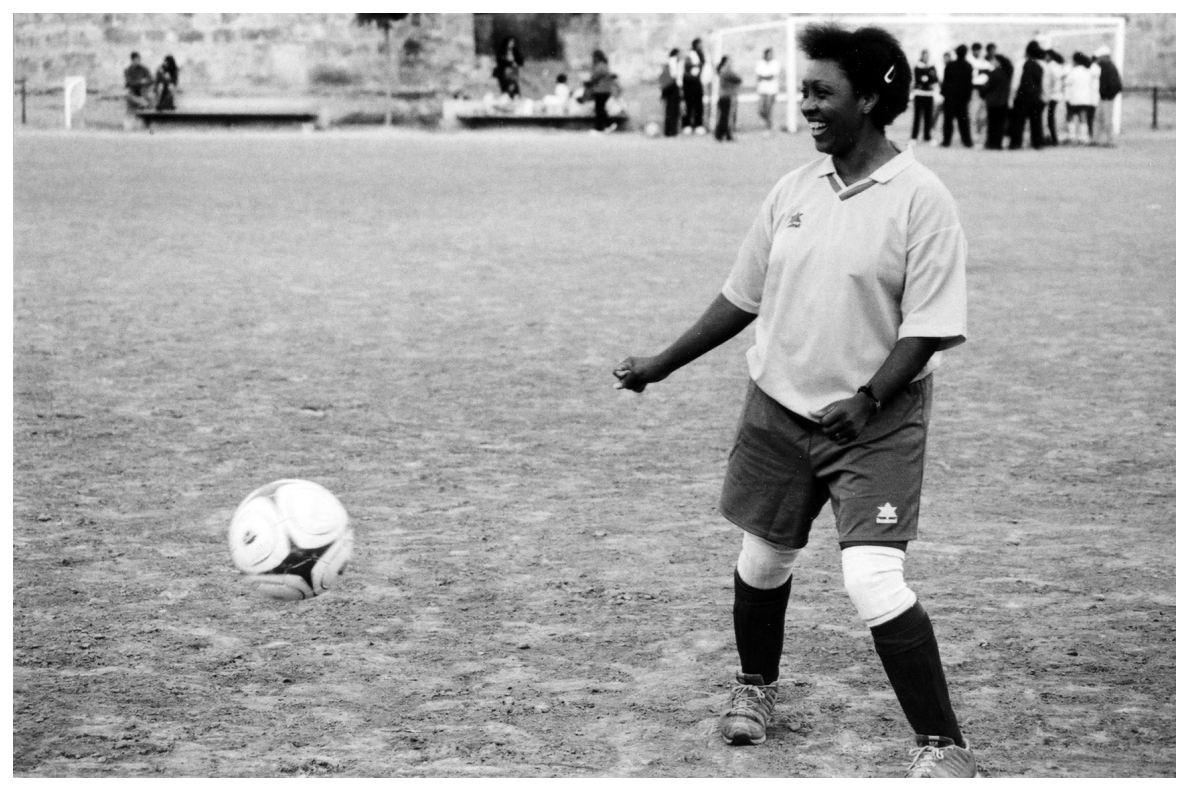

y la creación de relaciones sociales que conlleva el deporte. Estos vínculos sociales, más sólidos y encarnados gracias a la actividad física, refuerzan la menguada libertad que viven en otros terrenos.

\section{Referencias bibliográficas}

BalibReA, Kety y SANTOS, Antonio. Deporte en los barrios: integración o control social, Valencia, Servicio de publicaciones de la Universitat Politècnica de València, 2011.

BARTHES, Roland. La cámara lúcida. Nota sobre la fotografía. Barcelona, Paidós, 1989.

Bourdieu, Pierre. Un Arte Medio: ensayo sobre los usos sociales de la fotografía, Barcelona, Ed.Gustavo Gili, 2003.

DURÁN, Javier. (coord.) Actividad física, deporte e inmigración. El reto de la interculturalidad. Madrid, Dirección General de Deportes, Comunidad de Madrid, 2009.

GaRCía FerRANDO, Manuel y LloPis, Ramón. Ideal democrático y bienestar personal. Encuesta sobre los hábitos deportivos en España 2010. Madrid, Consejo Superior de Deportes y Centro de Investigaciones Sociológicas, 2011.

HeINEMANN, Klaus. «Deporte para inmigrantes: ¿instrumento de integración?» Apunts. Educació Física i Esport, no 68. (2002). 
LleiXÁ, Teresa y Soler, Susanna. Actividad física y deporte en sociedades multiculturales integración o segregación? Barcelona, ICE- Horsori, 2004

MAZA Gaspar. (coord.) Deporte, actividad física e inclusión social. Una guía para la intervención social a través de las actividades deportivas. Consejo Superior de Deportes, Madrid, 2010 (Consultada 13-11-2012.)

http://www.planamasd.es/sites/default/files/programas/medidas/actuaciones/ WEB-GUIA+I.pdf)

MAZA, Gaspar. «El deporte y su papel en los mecanismos de reproducción social de la población inmigrada extranjera». Apunts. Educació Fisica i Esports, $\mathrm{n}^{\mathrm{o}}$ 68. (2002).

Medina, X. «Esport, immigració i interculturalitat». Apunts. Educació Fisica i Esports $\mathrm{n}^{\circ} 68$. (2002).

SAnTos, Antonio. «Exclusión social y deporte», Barcelona Metropolis $\mathrm{n}^{\circ} 81$, (2011), pp. 57-59. (consultada 13-11-2012) [http://w2.bcn.cat/bcnmetropolis/arxiu/es/page6a69.html?id=23\&ui=476\&prevNode=33\&tagId=243]

Santos, Antonio. Balibrea, K. y otros. Mujeres en forma contra la exclusión, (2004) Valencia, Dirección General de la Mujer, Generalitat Valenciana, (2004) [http://www.uv.es/dis/1.pdf, consultada el 1-10-2012]

SONTAG, Susan. Sobre la fotografía, Barcelona, Edhasa,1981. 